УДК 316

$10.17213 / 2075-2067-2021-4-36-44$

\title{
ФУНКЦИОНАЛЬНАЯ НЕГРАМОТНОСТЬ: АКТОРЫ ВЫСШЕГО ОБРАЗОВАНИЯ, РИСКИ ОБРАЗОВАТЕЛЬНОЙ И ПРОФЕССИОНАЛЬНОЙ НЕКОМПЕТЕНТНОСТИ
}

\author{
(C) 2021 г. Е. В. Загороднюк, Н. С. Иваненко
}

\section{Южнн-Российский государственный политехнический университет (НПИ) имени М. И. Платова, г. Новочеркасск, Россия}

Целью заявленной статьи является анализ функииональной неграмотности в российском выстем образовании как уже не новой реальности, характеризующей профессиональные позици акторов высшего образования: студентов и отчасти профессорско-преподавательского состава.

Методология исследования определяется, во-первых, пониманием функииональной неграмотности как массового явления российского общества, приобретшего характер институционализачии, во-вторых, субъектностью, включением в обыденные и профессиональные стратегии акторов выстего образования алгоритма «функциональной неграмотности», в-третьих, обоснованием субъектно-деятельностной парадигмы, содержащей возможность анализа институциональных (объективных) и деятельностных (субъективныхх) факторов функциональной неграмотности.

Результаты исследования. Функциональная неграмотность в широком социальном контексте стала следствием формирования парадоксального человека, в котором существуют противоречивые явления на уровне расхождения между декларируемыми позициями и схемами практической деятельности. В контексте развития отечественного высшего образования происходит смещение приоритетов на количественные показатели дипломированных специалистов и моду на рыночные профессии как наиболее привлекательные для будущих студентов. Авторы статьи делают вывод, что функииональная неграмотность, которая содержит деструктивное влияние на траекторию развития выстего образования, закрепляя заниженные когнитивные и профессиональные установки акторов высшего образования, не станет «исчезнувшей» в среднесрочный период, поскольку для прохождения точки перелома требуются системные структурные и функциональные изменения.

Ключевые слова: функииональная неграмотность; отечественное высшее образование; акторы высшего образования; массовые профессии; рыночные профессии; функииональный специалист.

\section{FUNCTIONAL ILLITERACY: ACTORS OF HIGHER EDUCATION, RISKS OF EDUCATIONAL AND PROFESSIONAL INCOMPETENCE}

\author{
(C) 2021 E. V. Zagorodnyuk, N. S. Ivanenko
}

\section{Platov South Russian State Polytechnic University (NPI), Novocherkassk, Russia}

The purpose of the stated article is to analyze functional illiteracy in Russian higher education as no longer a new reality that characterizes the professional positions of actors of higher education: students and, in part, the teaching staff. 
The methodology of the research is determined, firstly, by the understanding of functional illiteracy as a mass phenomenon of Russian society, which has acquired the character of institutionalization, secondly, by the subjectivity, the inclusion of the "functional illiteracy" algorithm in the everyday and professional strategies of higher education actors, and thirdly, by the justification of the subject-activity paradigm, which contains the possibility of analyzing institutional (objective) and activity (subjective) factors of functional illiteracy.

The results of the study. Functional illiteracy in a broad social context has become a consequence of the formation of a paradoxical person, in which there are contradictory phenomena at the level of discrepancy between the declared positions and schemes of practical activity. In the context of the development of domestic higher education, there is a shift in priorities to the quantitative indicators of certified specialists and the fashion for market professions as the most attractive for future students. The authors of the article conclude that functional illiteracy, which contains a destructive influence on the trajectory of higher education development, fixing the underestimated cognitive and professional attitudes of higher education actors, will not «disappear» in the medium term, since systemic structural and functional changes are required to pass the turning point.

Key words: functional illiteracy; domestic higher education; actors of higher education; mass professions; market professions; functional specialist.

Постановка проблемы. В российском высшем образовании становится очевидным, что на состояние качества, перспективы развития высшего образования в России влияет функциональная неграмотность, то явление, которое российский социолог Ж. Т. Тощенко определяет как отсутствие образовательной подготовки и, что более важно, как неразвитость навыков и способностей к самообразованию [8]. Будущее высшей школы измеряется новыми поколениями акторов высшего образования: студентами и профессорскопреподавательским составом. Изменился состав и уровень образовательной подготовки будущих студентов, что связано с влиянием социально-дифференцирующих, социально-территориальных, социально-профессиональных факторов. Функциональная неграмотность на этом уровне проявляется в расхождении между формальным соответствием образовательным нормам высшей школы и уровнем образовательной компетентности, необходимой для успешного прохождения профессиональной социализации.

Это выявляется в том, что, во-первых, будущие студенты ориентируются в основном на «диплом», а не на «знание», то есть не включают в приоритеты своей учебно-про- фессиональной деятельности когнитивный (познавательный) интерес, определяющий повышение грамотности как алгоритм деятельности. Такой ситуации способствует сложившийся в российском обществе образовательный дискурс, в котором важной является нуминационная (элективная) функция высшего образования и восприятие по критериям «стилистики»: модности, престижности, доходности. Грамотность в этом контексте является необязывающим компонентом и рассматривается акторами высшего образования в качестве идеального, а не работающего конструкта. Во-вторых, это является следствием того, что мы обозначили как спад когнитивного интереса будущих студентов, конвертация образовательных стандартов в защитные механизмы профессиональной некомпетентности. То есть акторы высшего образования определяют свое отношение к профессиональной социализации как признание «модальных» образовательных стандартов, того, что необходимо для прохождения обучения, но не ориентирует на самообразование. В-третьих, информатизация высшего образования не только открыла новые возможности для освоения профессии, но и создала риски внедрения «клипового мышления», использование информационных 
технологий для замещения образования и самообразования, снижения интереса к повышению профессиональной квалификации [1].

Таким образом, актуальность данной проблемы для развития высшего российского образования, связанная с анализом реальных сложностей функциональной неграмотности в российском образовании, является обоснованной. Следует учитывать различия между функциональной неграмотностью и функциональной безграмотностью, так как функциональная неграмотность определяется объектно-субъектными параметрами высшего образования, в то время как функциональная безграмотность является следствием процессов институционального и коммуникативного характера. Функциональная безграмотность определяется снижением качества социального взаимодействия в общественной жизни и в тенденции маргинализации профессионального статуса, потерей доверия к профессионализму как общественной ценности. Это важные моменты, которые должны найти место в общественной дискуссии, но не входят в проблематику нашей статьи, ориентированой на функциональную неграмотность акторов высшего образования, которые могут быть или не быть функционально неграмотными в зависимости от запроса на функциональную грамотность, динамику рынка труда, конвертации экономического и социального капитала. Иными словами, функциональная неграмотность является барьером на пути профессиональной ориентации и профессиональной регуляции и саморегуляции. Российские исследователи, отмечая неоднозначность процесса цифровизации в россиском обществе, признают, что необходимость вхождения России в русло технологической революции находит наибольшую поддержку и понимание в сфере науки и образования [5]. Однако необходимым условием становится цифровая грамотность акторов образования, что акцентирует внимание на функциональной грамотности, общеобразовательной компетенции как набора знаний и умений, необходимых для эффективного использования цифровых технологий. Возникает замкнутый круг: акторы высшего образования с уровнем функциональной неграмотности не могут в перспективе претендовать на рост профессиональной карьеры, и в то же время функциональная неграмотность не позволяет использовать ресурсы самообразования и перехода на стабильные когнитивные практики.

Методология исследования. В рамках изучаемого явления функциональной неграмотности важно посмотреть на нее, как на новую социальную реальность, требующую интерпретации новых социальных фактов в сфере высшего образования. Исходя из этого положения, можно говорить о том, что здесь вполне уместна схема разделения на «объективистов» и «деятельностников». Это вмещается в рамки социологической классики, делая необходимым понимание того, что функциональная неграмотность не является результатом системных изменений, ориентируя на структуры деятельности акторов высшего образования.

Если мы попытаемся сформулировать методологический выбор на основании исследования функциональности/дисфункциональности высшего образования, исследовательские усилия направляются на анализ процессов профессионального воспроизводства в системе высшего образования, перспектив устройства выпускников высшей школы, реализации социальных функций высшего образования. Это является источником социально полезной информации, но функциональная неграмотность объективируется, становится структурным обстоятельством, не зависимым от акторов высшего образования.

На наш взгляд, функциональная неграмотность является субъективным индикатором, отражающим реальные схемы восприятия и оценки высшего образования в российском обществе. Действительно, несмотря на внешний сохранившийся фон позитивного отношения к высшему образованию как базовому условию жизненной карьеры, к социальному ресурсу личности, есть два обстоятельства, которые обращают наше внимание на субъектно-деятельностную методологию [2]. Первое связано с изменением отношения к высшему образованию как способу получения диплома, отсюда принятие формулы доступного и экономного образования, позволяющего пройти курс профессиональной социализации без формирования способностей к самостоятельной профессиональной подготовке. Второе: функциональная негра- 
мотность закрепляет привычку обходиться без сложных схем и решений, пользоваться существующими функциональными, эквивалентными знаниями, тем, что является обязательным в учебных программах и курсах. Такая ситуация приводит к тому, что вымывается слой функционально-компетентных преподавателей как акторов высшего образования, тех, кто реально в состоянии вводить новые учебные курсы и программы и быть референтами для студенческой молодежи в этом направлении.

Поэтому методология исследования основывается на принятии субъектно-деятельностного подхода, содержащего критерии функциональной грамотности/неграмотности акторов высшего образования как субъектов образовательно-профессиональной деятельности, способности к самообразованию и усложнению образовательных программ, отношение к вопросам, стимулирующим профессиональное творчество, готовность к профессиональной социализации на уровне совместных профессиональных и деловых коммуникаций в том, что называется преодолением избыточной индивидуализации высшего образования.

Таким образом, методология исследования определяется тремя моментами: во-первых, пониманием функциональной неграмотности как массового явления российского общества, приобретшего характер институционализации, во-вторых, субъектностью, включением в обыденные и профессиональные стратегии акторов высшего образования алгоритма «функциональной неграмотности», в-третьих, обоснованием субъектно-деятельностной парадигмы, содержащей возможность анализа институциональных (объективных) и деятельностных (субъективных) факторов функциональной неграмотности.

Материалы исследования. Функциональная неграмотность акторов высшего образования в российском обществе с одной стороны является следствием глобальных изменений, с другой - результатом специфических российских обстоятельств. На глобальном уровне функциональная неграмотность характеризуется изменением в характере жизнедеятельности миллионов людей, вовлеченных в процесс использова- ния дешевого, неквалифицированного труда и формирования у индивида «исполнительских» качеств, не требующих формирования широких профессиональных горизонтов.

В российском контексте функциональная неграмотность воспроизводится в условиях коммерционализации образовательных услуг, изменения набора профессий, что связано с понижением авторитета сложных профессий, требующих профессиональной грамотности и постановки на «конвейер» краткосрочной профессиональной подготовки в сфере менеджмента и услуг.

Эти факторы отражаются в настроениях акторов высшего образования, что подтверждается результатами актуальных социологических исследований, фиксирующих на протяжении длительного пятилетнего периода рост профессиональных предпочтений будущих студентов, определяемых оценкой субъективных шансов как достаточных для освоения несложной профессии. Если еще два десятилетия назад мы могли быть свидетелями хотя и падающего, но постоянного интереса к высшей школе как источнику знаний, нынешние два постсоветских поколения молодежи определяют свое отношение к высшему образованию прагматически, проводят разделение между социальным взрослением, связанным с поиском самостоятельных заработков и возможностью обретения жизненных благ, и высшей школой, где студент вынужден выполнять субдоминантные функции, соблюдать нормы образования, связанные с прохождением процедур аттестации (номинации), демонстрировать соблюдение правил образовательной деятельности и, что не менее важно, находиться в состоянии формальной лояльности по отношению к профессорско-преподавательскому составу, который по совокупности объективных факторов нацелен на сохранение и расширение состава студенчества, что обеспечивает необходимую учебную нагрузку и сохранение ставок. Показатели качества образования если и проявляются, то на уровне введения инновационных программ и курсов, требующих ревизии знаний и способностей акторов высшего образования. Однако эффект «новизны» действует в течение 2-3 лет согласно правилу адаптации, необходимости совместимости старых и новых программ в рамках воспро- 
изводства институциональных параметров высшей школы. В глобальном пространстве получил распространение лозунг «формирование общества, основанного на знании». Подчеркивается, что знание является одним из ключевых факторов развития [9]. Однако, провозглашенная позиция, отмечая повсеместное повышение мобильности квалифицированных людских ресурсов, проходит мимо проблемы функциональной неграмотности, формирующейся как раз в рамках разрыва между потребностью в квалифицированных ресурсов и механизмов воспроизводства функциональной неграмотности как следствие ресурсного неравенства общества.

Чтобы формировались новые институциональные практики акторов высшего образования, требуется консенсус относительно целей и задач российской высшей школы, но по усмотрению попытки реформирования определяются функциональными соображениями (финансовыми, организационными, структурными): в сложившемся контексте функциональная неграмотность открыто не приветствуется, но допускается, так как создает фон резистентности изменениям, способным кардинально пересмотреть требования и нормы высшего образования [4]. Однако, если обратиться к динамике возрастной структуры высшего образования, можно отметить, что с 90-х годов XX века углубляется тенденция «старения» профессорско-преподавательского состава, и одним из следствий можно считать распространение функциональной неграмотности, связанное с тем, что одновременно действуют факторы на довершение профессиональной карьеры и рост неподъемных расходов для профессорско-преподавательского состава, связанных с обретением новой литературы, компьютерной техники, дороговизной проживания в крупных городах, где проводятся курсы повышения профессиональной квалификации [7].

Судя по результатам социологических исследований, интерес акторов высшего образования к профессиональному росту не исчез, напротив, он усиливается в связи с процессами информатизации и дигитализации высшего образования. Однако при этом отмечается скептицизм относительно судеб профессионального образования, поскольку респонденты отмечают отставание препода- вателей от новейшей литературы, неспособность наладить новые формы коммуникаций со слушателями, сформировать представления о динамике преобразования в высшей школе.

Как отмечают авторы специализированного исследования по профессиональной компетентности в российском высшем образовании, для них приоритетной является разработка компетентностного подхода, обеспечивающего формирование базовых и инструментальных компетенций [10]. Но, на наш взгляд, к данной позиции необходимо относиться без восторга и с критической оценкой, поскольку вопрос о функциональной неграмотности акторов высшего образования не решается, а наоборот, уводится в сторону.

Введение дискурса компетентности высшего образования является непроработанным, связанным с механическим заимствованием зарубежных образцов. В результате накопилась масса литературы по компетенциям, и профессорско-преподавательский состав вынужден заниматься значительной бумажной работой по измерению компетентности студентов. При этом возникает еще одна проблема, связанная с тем, что показатели компетентности не стимулируют преодоление профессиональной неграмотности, то есть акторы высшего образования нацеливаются на сознательное принятие формулы сужения профессиональных и образовательных горизонтов, исходя из нормативов компетентности.

Другими словами, ситуация с компетентностями замораживает уровень функциональной неграмотности: по результатам социологических исследований можно сделать вывод о том, что новации с компетентностью в высшей школе не привели к росту образовательной и профессиональной активности, расширили сферу имитируемости показателей, и, таким образом, функциональная неграмотность акторов высшего образования как феномен воспроизводства институциональных обстоятельств закрепляется превнесением в настроения респондентов безразличия к вопросам профессиональной карьеры. По их мнению, успех профессиональной карьеры акторов высшего образования определяется различными формальными и неформальными факторами, но среди них владение компетенциями не означает 
профессиональной компетентности. Являясь формой отчетности, «графа компетентности» входит в статус нормы, не нацеливая на самообразование студентов и профессорско-преподавательский состав. Результаты многолетних исследований М.К. Горшкова и Ф.Э. Шереги показывают, что для определения перспектив молодежи важной является реализация ею своей роли как субъекта воспроизводства социальной структуры. Следовательно, интерес представляют позиции молодежи относительно шансов в образовании, и, как отмечают авторы исследования, социокультурный барьер влияет на ограничение доступа к функциональной грамотности, т.е. студенты (а речь идет о сфере среднего профессионального образования) делают вынужденный образовательный выбор (83\% студентов СПО учились в средней школе) [2]. Важно, что ситуация неравенства жизненных шансов формирует функциональную неграмотность, когда невостребованным является такое профессиональное образование, которое перспективно для воспроизводства статуса родителей или восходящей социальной мобильности. Вероятно, для того чтобы выявить условия, позволяющие определить стратегию нейтрализации функциональной неграмотности в высшем образовании, должна быть разработана система мер, связанная с поддержанием эффективности работы вузов в целом и формирования потребности в профессионализме у подавляющего большинства акторов высшего образования [10].

Таким образом, можно сделать вывод о том, что в пространстве отечественного высшего образования наблюдаются разнонаправленные тенденции. С одной стороны, проявляются показатели функциональной неграмотности, что связано с совокупностью обстоятельств, среди которых решающее влияние имеют социальные парадоксы, расхождение между реальными шансами претендентов и действующих акторов в системе высшего образования и формальное образовательное равенство, которое внешне уравнивает шансы акторов, исходя из формулы гражданских прав, но вместе с тем «камуфлирует» разность семейного капитала. С другой стороны, есть тренд роста сложной профессиональной подготовки, определяемой потребностью в высококвалифицированных социальных нишах, особенно в контексте формирования информационного сектора экономики, процессов, связанных с функциональной грамотностью, способностью применить знания, и не только информационного свойства, для профессиональной карьеры.

Функциональная неграмотность воспроизводится как следствие «лага» между равенством по желаниям и неравенством по возможностям, то есть акторы высшего образования допускают функциональную неграмотность или отстраняются от противодействия ее влиянию, если для них очевидно, что шансы на высокий профессионализм исчезают или не закрепляются в контексте востребованности на понижение качества знаний, на исполнение деятельности, содержащей набор алгоритмов, влияющих на акторов высшего образования как «сигнал» к тому, чтобы большую часть не накапливать, а освобождаться от них как бесполезных, а иногда мешающих, заменяемых ими, профессиональных позиций.

Казалось бы, это противоречит культу знаний высшей школы, что характеризуют саму сущность высшего образования именно как высшего, а не среднего и базового. Однако здесь нет ничего удивительного, так как современная высшая школа во многом потеряла черты академичности, перестала быть «инкубатором» талантов, нацелена на адаптивные профессиональные схемы, которые могут выглядеть внешне нецелесообразными, но основываются на логике востребованности того, что в современном мире ведущий тренд имеет массу неквалифицированного труда. Сразу же оговоримся, что современный неквалифицированный труд имеет несколько иное содержание и смысл, чем традиционный, связанный преимущественно с тяжелой физической работой (эффект грузчика). Для современного неквалифицированного труда, определяемого функциональной неграмотностью, свойственна актуализация технологических и актуальных факторов, но в секвестированном формате, экономии на формировании знаний и способностей, создающих завышенные ожидания акторов высшего образования, что приводит к социальной фрустрации.

Ныне характер функциональности социальных акторов предполагает все больше 
импровизации и практически ограничен, по мнению П. Бурдье, только игабитусами социальным опытом, определяющим предрасположенностью к действию [3]. Смысл этого положения состоит в том, что функциональность социальных акторов есть соответствие функциональной грамотности, то есть способности исполнять набор предписанных профессиональных действий, но как отмечается, актуализируются механизмы импровизации, то есть ухода от предрасположенности, исходя из формулы опыта, социальной доксы.

Именно переход от ортодоксальности как меры знания определяет позиции акторов высшего образования, для которых академические знания не являются ни стартовой площадкой профессиональной карьеры, ни тем незаменимым пакетом знаний на «все ситуации и случаи». Актор высшего образования обязан быть функциональным, то есть не сопротивляться закрепившимся стандартам передачи и переработки знаний, но в процессе их усвоения более привлекательным оказывается импульс интерпретации, возможности адаптации к социальному опыту, к тому, что социальный опыт «селекционирует» знания, выстраивает в определенную иерархию востребованности, и объективно актор высшего образования принимает функциональную неграмотность как условие интерпретации знаний [6]. Взятый в 90-е годы XX века курс на осовременивание российского высшего образования, на наш взгляд, имея неразработанность механизмов перехода от высшего образования индустриального типа, предусматривающего в качестве требования выпуск массовых функциональных специалистов, привел к установке на «рыночные» профессии (менеджеры, юристы, экономисты). Однако произошла девальвация профессиональных знаний, так как в процесс конкурентности за будущих студентов вступили вузы, не имеющие либо опыта профессиональной подготовки, либо условий для формирования профессиональных специалистов.

Выводы. Как результат, наметилась тенденция снижения качества образовательных стандартов, что являлось объяснимым в условиях ограниченности финансовых, кадровых и временных ресурсов для перестройки высшего образования, и переключение внимания не на качество знаний, а на количество студентов и доступ к финансовым ресурсам. В этом смысле функциональная неграмотность перестала восприниматься как явление, обозначающее кризис высшего образования, так как приоритеты высшего образования определялись и до сих пор определяются количественными показателями и не содержат стимула для перехода к системе целенаправленной функциональной грамотности в ее современном смысле. Функциональная неграмотность не вызывает раздражения и непринятия, соответствуя общему спаду образовательной подготовки в российском обществе. Учитывая, что в отечественном высшем образовании сложилась дифференциация на элитные вузы, работающие на перспективу высокой профессиональной карьеры, и вузы, ориентированные на критерии доступности высшего образования, нельзя ожидать скорейшего поворота высшей школы к требованиям функциональной грамотности, к тому, чтобы в новых экономических условиях акторы высшего образования являлись группой, референтной в рамках нейтрализации ограничения деструктивных влияний функциональной неграмотности. В лучшем случае, мы можем стать свидетелями затяжного процесса «дрейфа» к берегам функциональной неграмотности, которая является смягченным вариантом снижения качества отечественного высшего образования.

\section{Литература}

1. Актуальные проблемы образования: Сборник научных трудов / Науч. ред. Д.Л. Константиновский, Г.А. Чередниченко. - М.: Реглант, 2003. - 232 с.

2. Горшков М.К., Шереги Ф.Э. Молодежь в зеркале социологии. К итогам многолетних исследований: монография. - М.: ФНИСЦ РАН, 2020. - 688 c.

3. Кравченко С.A. Социологическое знание через призму «стрелы времени»: востребованность гуманистического поворота: монография. - М.: МГИМО-Университет, 2015. - 342 c.

4. Малинкович В.Д. Век вывихнут... Распалась связь времен. - М.: ИГПИ, 2008. $352 \mathrm{c}$. 
5. Россия: многообразие культур и глобализация / Ответ. ред. И. К. Лисеев. - М.: «Канон+» РООИ «Реабилитация», 2010. — 448 с.

6. Сорокина Н.Д. Образование в современном мире (социологический анализ): монография. - М.: «Экономика и финансы», 2004. - $224 \mathrm{c}$.

7. Столицы и регионы в современной России: мифы и реальность пятнадцать лет спустя / Отв. ред. М.К. Горшков, Н.Е. Тихонова. - М.: Весь Мир, 2018. - 312 с.

8. Тощенко Ж. T. Парадоксальный человек. - М.: Гардарики, 2001. - 398 с.

9. Формирование общества, основанного на знаниях. Новые задачи высшей школы/ Пер. с англ. А. Сальникова. - М.: «Весь Мир», 2003. - 232 c.

10. Quality, Social Justice and Accountability in Education Worldwide / BCES Conference Books. - 2015. - Vol. 13. - №2. - 208 p.

\section{References}

1. Aktual'nye problemy obrazovanija: Sbornik nauchnyh trudov [Actual problems of education: Collection of scientific works] / Nauch. red. D.L. Konstantinovskij, G.A. Cherednichenko [In D.L. Konstantinovsky, G.A. Cherednichenko (eds.)]. - Moscow: Reglant, 2003. - 232 p.

2. Gorshkov M. K., Sheregi F. Je. Molodezh' $\mathrm{v}$ zerkale sociologii. $\mathrm{K}$ itogam mnogoletnih issledovanij: monografija [Youth in the mirror of sociology. To the results of long-term research: monograph]. - Moscow: FNISC RAN, 2020. - 688 p.

3. Kravchenko S.A. Sociologicheskoe znanie cherez prizmu «strely vremeni»: vostrebovannost' gumanisticheskogo povorota: monografija [Sociological knowledge through the prism of the «arrow of time»: the demand for a humanistic turn: monograph]. - Moscow: MGIMO-Universitet, 2015. - $342 \mathrm{p}$.

4. Malinkovich V.D. Vek vyvihnut... Raspalas' svjaz' vremen [The century is dislocated... The connection of times has broken up]. Moscow: IGPI, 2008. - $352 \mathrm{p}$.

5. Rossija: mnogoobrazie kul'tur i globalizacija [Russia: diversity of cultures and globalization] / Otvet. red. I.K. Liseev [In I.K. Liseev (eds.)]. - Moscow: «Kanon+» ROOI «Reabilitacija», 2010. - $448 \mathrm{p}$.

6. Sorokina N.D. Obrazovanie v sovremennom mire (sociologicheskij analiz): monografija [Education in the modern world (sociological analysis): monograph]. - Moscow: «Jekonomika i finansy», 2004. - $224 \mathrm{p}$.

7. Stolicy i regiony v sovremennoj Rossii: mify i real'nost' pjatnadcat' let spustja [Capitals and regions in modern Russia: myths and reality fifteen years later] / Otv. red. M.K. Gorshkov, N.E. Tihonova [In M.K. Gorshkov, N.E. Tikhonova (eds.)]. - Moscow: Ves' Mir, 2018. - $312 \mathrm{p}$.

8. Toshhenko Zh. T. Paradoksal'nyj chelovek [Paradoxical man]. - Moscow: Gardariki, 2001. - 398 p.

9. Formirovanie obshhestva, osnovannogo na znanijah. Novye zadachi vysshej shkoly [Formation of a knowledge-based society. New tasks of the higher school] / Per. s angl. A. Sal'nikov [Translated from the English by A. Salnikov]. Moscow: «Ves' Mir», 2003. - 232 p.

10. Quality, Social Justice and Accountability in Education Worldwide / BCES Conference Books. - 2015. - Vol. 13. - №2. - 208 p. 


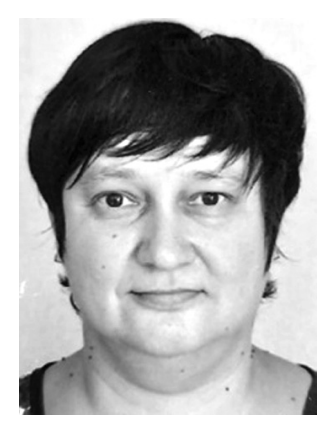

Загороднюк Елена Вячеславовна - кандидат технических наук, доцент кафедры «Социальные и гуманитарные науки» Южно-Российского государственного политехнического университета (НПИ) имени М.И. Платова.

Zagorodnyuk Elena Vyacheslavovna - Candidate of Engineering Sciences, Associate Professor of the Department of «Social and Humanitarian Sciences», Platov South Russian State Polytechnic University (NPI).

346411, г. Новочеркасск, ул. Народная, 62/2, кв. 57

62/2 Narodnaya st., app. 57, 346411, Novocherkassk, Russia E-mail: zagor-e.v@yandex.ru

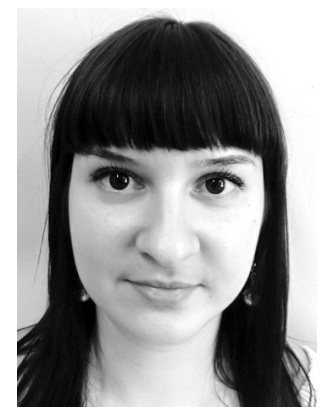

Иваненко Наталия Сергеевна - кандидат социологических наук, доцент кафедры «Социальные и гуманитарные науки» Южно-Российского государственного политехнического университета (НПИ) имени М.И. Платова. Сфера научных интересов - социология молодежи, процессы дифференциации в молодежной среде, социальная помощь и социальная поддержка молодежи, деловые коммуникации в сфере бизнеса и предпринимательства.

Ivanenko Natalia Sergeevna - Candidate of Sociological Sciences, Associate Professor, Department of Social Sciences and Humanities, Platov South Russian State Polytechnic University (NPI). Research interests - sociology of youth, processes of differentiation among youth, social assistance and social support for youth, business communications in the field of business and entrepreneurship.

346429, г. Новочеркасск, ул. Красный Спуск, 30, кв. 6 30 Krasny Spusk st., ap. 6, 346429, Novocherkassk, Russia E-mail: 79043483051@yandex.ru 